\title{
Sensibilidade de conídios de Beauveria bassiana a fatores abióticos após sucessivos cultivos in vitro
}

\section{Sensitivity of Beauveria bassiana conidia to abiotic factors after successive in vitro subcultures}

\author{
Janaína Zorzetti ${ }^{1 *}$; Patrícia Helena Santoro ${ }^{2}$; \\ Kelly Christiane Constanski ${ }^{1}$; Pedro Manuel Oliveira Janeiro Neves ${ }^{3}$
}

\begin{abstract}
Resumo
O objetivo deste trabalho foi avaliar o efeito de sucessivos cultivos in vitro, de isolados de Beauveria bassiana, em diferentes condições nutricionais, sobre a tolerância à temperatura e à radiação UV e a sensibilidade ao fungicida azoxistrobina. $\mathrm{O}$ fungo foi inicialmente inoculado em adultos de Alphitobius diaperinus (Coleoptera: Tenebrionidae), e após o seu desenvolvimento, os conídios foram multiplicados nos meios BDA (batata, dextrose, ágar) e MPE (meio para a produção de esporos de Beauveria spp.), originando os conídios de primeiro cultivo $1^{\circ}(\mathrm{A})$, os quais foram sucessivamente multiplicados nos respectivos meios até o $20^{\circ}$ cultivo. Os conídios retirados do $20^{\circ}$ cultivo foram reinoculados no inseto, e após a esporulação, foram novamente multiplicados nos meios de origem, produzindo os conídios de $1^{\circ}(\mathrm{B})$. Foram selecionados para os ensaios, os conídios de $1^{\circ}(\mathrm{A}), 10^{\circ}, 20^{\circ}$ e $1^{\circ}(\mathrm{B})$ cultivos dos isolados CG 152 e Unioeste 40. Os cultivos sucessivos e as condições nutricionais do meio interferiram na fisiologia do fungo, e os isolados mostraram comportamentos diferentes entre si. Os cultivos em meio BDA proporcionaram maior termotolerância ao Unioeste $40 \mathrm{em}$ todos os cultivos, e ao CG 152 apenas após as inoculações no hospedeiro. B. bassiana foi sensível à radiação UV, e essa característica foi influenciada pelos cultivos nos diferentes meios. Ambos isolados foram mais tolerantes a radiação UV quando cultivados em MPE, enquanto apenas para o Unioeste 40 essa tolerância aumentou após a inoculação no hospedeiro. A sensibilidade de $B$. bassiana ao fungicida azoxistrobina foi afetada após os sucessivos cultivos em ambos os meios. Os conídios originados em MPE foram mais resistentes ao fungicida, e a inoculação no hospedeiro também aumentou essa tolerância. Esses resultados mostram que é possível aprimorar a eficiência de fungos no controle de pragas, através da seleção de um isolado virulento, manipulação de suas condições nutricionais durante o cultivo e da inoculação no hospedeiro. Palavras-chave: Controle biológico, fungos entomopatogênicos, tolerância à radiação UV, tolerância à temperatura
\end{abstract}

\begin{abstract}
The aim of this study was to evaluate the effect of in vitro, successive subcultures of Beauveria bassiana isolates in different nutritional conditions on conidia to temperature and UV radiation tolerance and on sensitivity to azoxystrobin fungicide. The fungus was initially inoculated in Alphitobius diaperinus (Coleoptera: Tenebrionidae) adults and after its development, the conidia were cultivated in PDA (potato dextrose agar) and MPE (medium to produce Beauveria spp. conidia) originating the first subculture
\end{abstract}

\footnotetext{
${ }^{1}$ Discentes do Curso de Doutorado em Agronomia, Universidade Estadual de Londrina, UEL, Londrina, PR. E-mail: jzorzetti@ hotmail.com; kconstanski@hotmail.com

${ }^{2}$ Pesquisadora Dr ${ }^{\mathrm{a}}$ do Instituto Agronômico do Paraná, IAPAR, Londrina, PR. E-mail: ph_santoro@yahoo.com.br

${ }^{3}$ Prof. Dr. do Programa de Pós-Graduação em Agronomia, Fitossanidade, Dept ${ }^{\circ}$ de Agronomia, UEL, Londrina, PR. E-mail: pedroneves@uel.br

* Autor para correspondência
} 
$1^{\text {st }}$ (A) conidia, which were successively multiplied in their media until the $20^{\text {th }}$ cultivation. Conidia taken from the 20th subculture were again inoculated in the insect and after sporulation they were once more multiplied in the media, producing the $1^{\text {st }}(\mathrm{B})$ conidia. For the tests, $1^{\text {st }}(\mathrm{A}), 10^{\text {th }}, 20^{\text {th }}$ and $1^{\text {st }}(\mathrm{B})$ conidia from the CG 152 and Unioeste 40 isolates were used. Successive subcultures and the medium nutritional conditions interfered on the fungus physiology, and the isolates showed different behaviors. The subcultures on PDA showed higher thermotolerance to Unioeste 40 in all subcultures and to CG 152 just after inoculation in the host. B. bassiana was sensitive to UV radiation, and this characteristic was influenced by the subcultures in different media. Both isolates were more tolerant to UV radiation when subcultivated on MPE, while just for the 40 Unioeste this tolerance increased after host inoculation. The $B$. bassiana sensitivity to azoxystrobin fungicide was affected after successive subcultures in both medium. Conidia originated in MPE were more resistant to fungicide and the host inoculation increased this tolerance. These results show that it is possible to enhance the fungi efficiency to control pests, through the selection of a virulent isolate, and handling their nutritional conditions during cultivation and host inoculation.

Key words: Biological control, entomopathogenic fungi, UV radiation tolerance, heat tolerance

\section{Introdução}

Os fungos entomopatogênicos exercem a função de controle de pragas em ambientes naturais e ecossistemas agrícolas, ocupando um lugar relevante na manutenção do equilíbrio ecológico. São promissores pelo amplo espectro de hospedeiros, possibilidade de serem formulados como biopesticidas e cultivados in vitro (LEITE et al., 2003).

A eficiência dos fungos no controle microbiano é fortemente influenciada pelas condições bióticas e abióticas (PELL et al., 2001), dentre essas, a temperatura elevada apresenta grande importância (KIM; JE; ROH, 2010). Ela pode afetar o metabolismo desses patógenos e alterar os processos de produção de enzimas e toxinas. Além disso, pode retardar o processo de germinação dos conídios de algumas espécies de fungos entomopatogênicos, como B. bassiana e de M. anisopliae (ALVES; LEUCONA, 1998; DEVI et al., 2005; RANGEL et al., 2005).

A radiação UV também é considerada um fator abiótico de grande impacto para os fungos entomopatogênicos, pois é capaz de causar danos e a total inativação dos conídios, reduzindo sua eficiência no controle de pragas (BRAGA et al., 2001). Isso ocorre porque a exposição à radiação UV pode danificar macromoléculas, como DNA, proteínas, biomembranas, RNA e ribossomos, causando atraso na germinação, inativação de conídios e, consequentemente, redução da atividade inseticida (RANGEL et al., 2006; CHELICO; KHACHATOURIANS, 2008).

A utilização de produtos fitossanitários de amplo espectro pode comprometer a eficiência de fungos entomopatogênicos. Entretanto, se forem seletivos aos agentes de controle biológico, podem ser utilizados como uma estratégia segura e eficiente em programas de manejo integrado de pragas, principalmente nas culturas onde a utilização destes produtos seja indispensável (ALVES et al., 1998).

Para que os fungos possam ser agentes de controle eficientes, independentemente da densidade populacional dos insetos, é necessário que exista um elevado potencial de inóculo na área, obtido por meio de aplicações inundativas no campo. Para isso precisam ser produzidos em grande quantidade, mantendo as características morfológicas e de virulência com custo acessível.

De maneira geral, podem ser facilmente cultivados em meio artificial (FERRON, 1985), contudo, esse processo exige que o patógeno seja cultivado por vários ciclos em meio de cultivo, o que pode causar alterações nas características de elevada virulência, esporulação e resistência a fatores abióticos. Os efeitos de sucessivas passagens in vitro variam entre isolados e espécies, e a manutenção dessas características é desejável 
para um agente de controle biológico produzido em massa (VANDENBERG; CANTONE, 2004).

Alguns autores recomendam passagens sucessivas dos fungos pelos seus hospedeiros, o que pode alterar, além da virulência, as características morfológicas como viabilidade, esporulação e composição química dos conídios (ALVES; PEREIRA, 1998; SERAFINI; BARROS; AZEVEDO, 2001). Já Latch (1976) não observou incremento na virulência de $M$. anisopliae e $B$. bassiana após passagem dos fungos sobre o inseto hospedeiro. Os resultados divergentes obtidos nos estudos sobre a influência dos sucessivos cultivos em características de fungos entomopatogênicos podem ser devido às variações intra e interespecíficas, uso de culturas monospóricas e condições nutricionais de cultivo.

Assim, o objetivo desse trabalho foi avaliar o efeito dos cultivos in vitro em diferentes condições nutricionais sobre a tolerância dos isolados de Beauveria bassiana à radiação UV e à temperatura, e sensibilidade a produto químico.

\section{Material e Métodos}

Os isolados multiespóricos de $B$. bassiana utilizados foram Unioeste 40 e CG 152, previamente selecionados para controle de Alphitobius diaperinus (Panzer) (Coleoptera: Tenebrionidae) (SANTORO et al., 2008). As cepas encontram-se armazenadas na Coleção de Entomopatógenos do Laboratório de Controle Microbiano da Universidade Estadual de Londrina. Os insetos adultos de A. diaperinus (Panzer) (Coleoptera: Tenebrionidae) foram coletados em aviários situados em Londrina, PR.

Inicialmente os conídios foram multiplicados em placas de petri com meio específico para a produção de esporos de Beauveria spp. (MPE) (ALVES et al., 1998). Os conídios produzidos na superfície do meio foram inoculados em insetos adultos de $A$. diaperinus por imersão em uma suspensão contendo $1,0 \times 10^{7}$ conídios $\mathrm{mL}^{-1}$ por $15 \mathrm{~s}$. Após a morte, os insetos foram acondicionados em câmara úmida $\left(25 \pm 1{ }^{\circ} \mathrm{C}\right)$ por cinco dias para a confirmação da mortalidade pelo fungo.

Após o desenvolvimento de $B$. bassiana sobre os insetos mortos ( $1^{\circ}$ ciclo), os conídios foram coletados e multiplicados nos meios BDA e MPE e acondicionados em câmara climatizada (25 \pm $1{ }^{\circ} \mathrm{C}$ ) por 10 dias, dando origem aos conídios de primeiro cultivo $1^{\circ}(\mathrm{A})$. Os conídios provenientes desse $1^{\circ}$ cultivo foram novamente multiplicados nos respectivos meios, dando origem aos de $2^{\circ}$ cultivo, e assim sucessivamente até o $20^{\circ}$ cultivo. Os conídios retirados do $20^{\circ}$ cultivo foram novamente inoculados em $A$. diaperinus. Após a morte desse inseto $\left(2^{\circ}\right.$ ciclo) e exteriorização do fungo produzido sobre os cadáveres, os conídios foram coletados e novamente multiplicados nos meios de origem (BDA ou MPE), produzindo conídios de primeiro cultivo após a segunda passagem pelo inseto, chamados de $1^{\circ}(\mathrm{B})$.

A cada cultivo, os conídios produzidos in vivo e in vitro foram recolhidos em tubos esterilizados e armazenados a $-6^{\circ} \mathrm{C}$. Devido ao tempo gasto para se obter todos os cultivos (aproximadamente 250 dias), foi necessário padronizar a idade dos conídios para eliminar alguma interferência decorrente do tempo de armazenagem. Para isso, os conídios produzidos no $1^{\circ}$ inseto, $9^{\circ}, 19^{\circ}$ e $2^{\circ}$ inseto armazenados a $-6^{\circ} \mathrm{C}$, foram novamente multiplicados em seus respectivos meios (BDA ou MPE), dando origem aos conídios de $1^{\circ}(\mathrm{A}), 10^{\circ}, 20^{\circ}$ e $1^{\circ}(\mathrm{B})$ cultivo, respectivamente, os quais foram utilizados em todos os testes. O meio MPE foi utilizado para a realização de todos os testes seguintes.

1. Tolerância à Radiação UV: A sensibilidade dos conídios à radiação UV foi avaliada pela quantificação de UFC, pois ainda que o método mais utilizado seja a germinação após a exposição (BRAGA et al., 2002; FARGUES et al., 1996; MOORE et al., 1993), os resultados obtidos poderiam ser subestimados, já que a exposição à radiação pode causar apenas um atraso na germinação dos conídios sobreviventes (NASCIMENTO et al., 2010). 
Sobre a superfície do meio foi inoculado $0,1 \mathrm{ml}$ da suspensão $\left(1 \times 10^{3}\right.$ conídios $\left.\mathrm{mL}^{-1}\right)$ obtida com os conídios provenientes dos sucessivos cultivos. Após a secagem da suspensão sobre o meio, as placas sem tampa foram colocadas em câmara de fluxo laminar, sob a parte central da lâmpada germicida (253,7 nm, Philips TUV, baixa pressão 30W) a uma distancia de $52 \mathrm{~cm}$. Após a exposição à radiação UV por um minuto, todas as placas foram fechadas e transferidas para câmara climatizada $\left(25 \pm 1{ }^{\circ} \mathrm{C}\right.$ e fotofase de $12 \mathrm{~h}$ ). O mesmo procedimento foi realizado para outras placas contendo meio MPE, entretanto essas não foram expostas à radiação UV, sendo considerados como uma testemunha. O número de colônias formadas foi avaliado após quatro dias. Foram realizadas seis repetições para cada cultivo.

2. Tolerância à Temperatura: Os conídios provenientes dos cultivos selecionados para os experimentos foram recolhidos em tubos de ensaio (2,5 $\mathrm{cm}$ de diâmetro x $8,5 \mathrm{~cm}$ de altura) esterilizados, vedados com filme plástico e acondicionados em câmara climatizada a $30{ }^{\circ} \mathrm{C}$ por 0 e 15 dias, no escuro. Suspensões $\left(1 \times 10^{3}\right.$ conídios $\mathrm{mL}^{-1}$ ) dos tratamentos foram inoculadas em placas de petri contendo o meio de cultivo. A tolerância à temperatura foi avaliada por contagem de unidades formadoras de colônias (UFC) após quatro dias. Foram realizadas cinco repetições para cada cultivo.

\section{Compatibilidade entre Azoxistrobina e} Beauveira bassiana: Selecionou-se o fungicida Azoxistrobina (Priori® $250 \mathrm{~g}$ i.a/L) para os testes de seletividade, por apresentar compatibilidade com alguns isolados de B. bassiana. A tolerância dos conídios ao fungicida foi avaliada por testes de UFC e germinação. Para o teste de germinação, foram utilizadas placas de Petri contendo meio de cultivo onde foi aplicado $0,1 \mathrm{~mL}$ da solução com fungicida ( $0,1 \mathrm{~mL}$ do fungicida em $1 \mathrm{~L}$ de água destilada) e espalhada com alça de drigalski. Após a secagem da solução, foi inoculado $0,1 \mathrm{~mL}$ de uma suspensão do fungo $\left(1 \times 10^{7}\right.$ conídios $\left.\mathrm{mL}^{-1}\right)$. A quantificação da germinação foi realizada após 20 horas (25
${ }^{\circ} \mathrm{C}$ ) em microscópio óptico (40x). Para avaliar as UFC, inoculou-se $0,1 \mathrm{~mL}$ da suspensão de conídios $\left(1 \times 10^{3}\right.$ conídios $\left.\mathrm{mL}^{-1}\right)$ sobre o meio MPE tratado superficialmente com a solução fungicida. Após quatro dias, quantificou-se o número de colônias formadas. Foram realizadas seis repetições por tratamento. Para as testemunhas, foram preparadas placas inoculadas apenas com as suspensões de conídios, sem a presença do fungicida.

4. Análises Estatísticas: Para todos os experimentos realizados foram utilizados delineamentos experimentais inteiramente casualizado em esquema fatorial $(2 \times 4)$ (meios de origem dos conídios $\times$ cultivos), os dados dos tratamentos foram submetidos à análise de variância e as médias foram comparadas pelo teste de Tukey $(p<0,05)$ utilizando-se o software SISVAR versão 5.1 (FERREIRA, 2007).

\section{Resultados e Discussão}

1. Tolerância à radiação UV: A interação entre os sucessivos cultivos e os diferentes meios foi significativa para ambos isolados (CG152: $F=9,30$; $\mathrm{gl}=3 ; \mathrm{p}=0,0001$ para não expostos à $\mathrm{UV} ; \mathrm{F}=0,244$; $\mathrm{gl}: 3 ; \mathrm{p}=0,8652$ para expostos à UV). (Unioeste 40: $\mathrm{F}=15,76 ; \mathrm{gl}=3 ; \mathrm{p}=0,000$ para não expostos à $\mathrm{UV} ; \mathrm{F}=8,20 ; \mathrm{gl}=3 ; \mathrm{p}=0,0002$ para expostos à UV). A viabilidade dos conídios foi reduzida após a exposição à radiação UV por um minuto, e os sucessivos cultivos afetaram sua sensibilidade. Para conídios do isolado CG 152, provenientes de BDA, e que não foram expostos à radiação $U V$, houve redução no número de UFC no $10^{\circ}$ cultivo. Após a segunda passagem pelo hospedeiro, em $1^{\circ}(\mathrm{B})$, houve um incremento nas UFC, superior aos demais cultivos. Para os conídios do isolado CG152, oriundos de MPE e não expostos à radiação UV, apenas em $1^{\circ}(\mathrm{B})$ houve um acréscimo em relação aos demais. Na comparação entre os meios, os conídios originados em MPE no $1^{\circ}(\mathrm{A})$ e $10^{\circ}$ cultivo originaram maior número de UFC que os de BDA (Tabela 1). 
Tabela 1. Unidades formadoras de colônias de Beauveria bassiana, com conídios provenientes de sucessivos cultivos em meio BDA (batata, dextrose, ágar) e MPE (meio para produção de esporos), não expostos e expostos à radiação ultravioleta por 1 minuto.

\begin{tabular}{|c|c|c|c|c|c|c|c|c|c|}
\hline \multirow{2}{*}{ Isolado } & \multirow{2}{*}{ Cultivo } & \multicolumn{4}{|c|}{${ }^{1}$ Não expostos à UV } & \multicolumn{4}{|c|}{${ }^{1}$ Expostos à UV } \\
\hline & & \multicolumn{2}{|c|}{ BDA } & \multicolumn{2}{|l|}{ MPE } & \multicolumn{2}{|c|}{ BDA } & \multicolumn{2}{|l|}{ MPE } \\
\hline \multirow{4}{*}{ CG 152} & $1^{\circ}(\mathrm{A})$ & $45.50 \pm 2.10$ & $\mathrm{Bb}$ & $56.67 \pm 1.97$ & $\mathrm{Ab}$ & $16.83 \pm 2.19$ & $\mathrm{Aa}$ & $23.00 \pm 3.58$ & $\mathrm{Aa}$ \\
\hline & $10^{\circ}$ & $27.83 \pm 3.70$ & $\mathrm{Bc}$ & $60.50 \pm 5.64$ & $\mathrm{Ab}$ & $7.83 \pm 2.05$ & $\mathrm{Bb}$ & $15.50 \pm 2.90$ & $\mathrm{Aa}$ \\
\hline & $20^{\circ}$ & $45.50 \pm 2.92$ & $\mathrm{Ab}$ & $52.83 \pm 3.11$ & $\mathrm{Ab}$ & $7.83 \pm 0.95$ & $\mathrm{Bb}$ & $17.33 \pm 2.54$ & $\mathrm{Aa}$ \\
\hline & $1^{\circ}(\mathrm{B})$ & $81.17 \pm 3.91$ & $\mathrm{Aa}$ & $78.50 \pm 2.94$ & $\mathrm{Aa}$ & $10.33 \pm 1.99$ & $\mathrm{Aab}$ & $16.33 \pm 1.50$ & $\mathrm{Aa}$ \\
\hline \multirow{4}{*}{ Unioeste 40} & $1^{\circ}(\mathrm{A})$ & $26.50 \pm 3.32$ & $\mathrm{Bab}$ & $65.33 \pm 3,51$ & $\mathrm{Aa}$ & $14.67 \pm 3.17$ & $\mathrm{Aa}$ & $10.17 \pm 4.32$ & $\mathrm{Ab}$ \\
\hline & $10^{\circ}$ & $22.67 \pm 1.03$ & $\mathrm{Bb}$ & $36.17 \pm 3.71$ & $\mathrm{Ab}$ & $6.50 \pm 0.93$ & $\mathrm{Aa}$ & $7.67 \pm 2.85$ & $\mathrm{Ab}$ \\
\hline & $20^{\circ}$ & $37.33 \pm 1.65$ & Aa & $40.50 \pm 3.42$ & $\mathrm{Ab}$ & $9.83 \pm 1.67$ & Aa & $6.17 \pm 2.41$ & $\mathrm{Ab}$ \\
\hline & $1^{\circ}(\mathrm{B})$ & $34.00 \pm 2.55$ & $\mathrm{Ba}$ & $66.17 \pm 3.20$ & $\mathrm{Aa}$ & $7.67 \pm 1.75$ & $\mathrm{Ba}$ & $26.17 \pm 2.66$ & $\mathrm{Aa}$ \\
\hline
\end{tabular}

${ }^{1}$ Médias ( \pm erro padrão) seguidas de mesma letra, minúscula na coluna e maiúscula na linha, não diferem entre si pelo teste de Tukey (p<0,05); [CG $152(\mathrm{CV}=15,07 \%)$ e $(\mathrm{CV}=39,69 \%)$; Unioeste $40(\mathrm{CV}=17,49 \%)$ e $(\mathrm{CV}=58,34 \%)$, para não expostos à UV e expostos à UV respectivamente]; $1^{\circ}(\mathrm{A})$ primeiro cultivo após a passagem por $A$. diaperinus; $1^{\circ}(\mathrm{B})$ primeiro cultivo após 20 passagens em meios e uma passagem pelo hospedeiro.

Fonte: Elaboração dos autores.

Para os conídios (CG 152) que foram expostos à radiação $\mathrm{UV}$, originados em meio $\mathrm{BDA}$, os mais tolerantes foram obtidos em $1^{\circ}(\mathrm{A})$. Já os mais sensíveis foram os de $10^{\circ}$ e $20^{\circ}$, que não diferiram entre si. Para os conídios oriundos de MPE, houve manutenção do número de UFC ao longo dos sucessivos cultivos, e não foi observado incremento após a segunda passagem pelo inseto. Na comparação entre os meios, o desenvolvimento em MPE foi mais favorável no $10^{\circ}$ e $20^{\circ}$, originando o dobro de UFC do que em BDA.

Houve variabilidade entre os isolados de B. bassiana em relação à tolerância à radiação UV após os sucessivos cultivos. Para o isolado Unioeste 40, proveniente do meio BDA e não expostos a radiação $\mathrm{UV}$, houve redução após o $10^{\circ}$ cultivo, com recuperação em $1^{\circ}(\mathrm{B})$. Os conídios (Unioeste 40) originados em MPE foram afetados negativamente no $10^{\circ}$ e $20^{\circ}$ cultivos, porém, após a passagem pelo inseto, o número de UFC aumentou, e não diferiu de $1^{\circ}(\mathrm{A})$. Os conídios produzidos em MPE apresentaram maior viabilidade em todos os cultivos, exceto no $20^{\circ}$, que não diferiu dos produzidos em BDA (Tabela 1).

Após a exposição do isolado Unioeste 40 à radiação UV, também houve redução na viabilidade dos conídios, entretanto, em meio BDA não houve diferença entre os sucessivos cultivos. Para os de MPE, houve manutenção na quantidade de UFC do $1^{\circ}(\mathrm{A})$ ao $20^{\circ}$ cultivo, porém, após a passagem pelo hospedeiro, foi observado um aumento de aproximadamente quatro vezes em relação ao $20^{\circ}$. Na comparação entre os meios, não houve diferença entre os cultivos, exceto em $1^{\circ}(\mathrm{B})$, onde MPE proporcionou maior tolerância dos conídios à radiação UV.

Entre as possíveis ferramentas que se pode utilizar durante as fases de crescimento e esporulação para elevar a tolerância dos conídios à radiação UV, está à exposição a estresse ambiental ou nutricional que, aparentemente, pode levar a produção de conídios com maior resistência à radiação UV em um fenômeno conhecido como proteção cruzada (RANGEL et al., 2008).

Entretanto, neste estudo, o isolado Unioeste 40 cultivado em meio BDA, com menor disponibilidade de nutrientes, mostrou menor tolerância à radiação UV do que em MPE, assim como para o isolado CG 152, onde a menor tolerância foi observada para os conídios oriundos de BDA, com menor disponibilidade de nutrientes. 
Para incrementar a tolerância à radiação UV, além da manipulação nutricional do meio de cultivo, é necessário selecionar isolados mais resistentes a esse fator. Alguns trabalhos mostram uma grande variabilidade na tolerância à radiação solar entre B. bassiana e M. anisopliae e até mesmo entre isolados da mesma espécie (FARGUES et al., 1996; FERNANDES et al., 2007). Os resultados obtidos no presente trabalho também mostraram variabilidade entre os isolados de $B$. bassiana em relação à tolerância à radiação UV, sendo o isolado CG 152, o que apresentou maior resistência.

2. Tolerância à temperatura: $\mathrm{A}$ exposição dos conídios a temperatura de $30{ }^{\circ} \mathrm{C}$, por 15 dias, foi suficiente para reduzir a sua viabilidade. A interação entre os sucessivos cultivos e os meios de cultivo foi significativa, afetando a qualidade dos conídios dos isolados CG 152 e Unioeste 40 após a exposição à temperatura elevada (CG152:
$\mathrm{F}=126,60 ; \mathrm{gl}=3 ; \mathrm{p}=0,0000$ para não expostos à temperatura elevada; $\mathrm{F}=10,244 ; \mathrm{gl}: 3 ; \mathrm{p}=0,0000$ para expostos à temperatura elevada). (Unioeste 40: $\mathrm{F}=3,948 ; \mathrm{gl}=3 ; \mathrm{p}=0,0167$ para não expostos à temperatura elevada; $\mathrm{F}=16,145 ; \mathrm{gl}=3 ; \mathrm{p}=0,0000$ para expostos à temperatura elevada). Para os conídios do isolado CG 152 provenientes do meio BDA, tanto os expostos, quanto os não expostos ao estresse da temperatura elevada, a maior tolerância foi observada após a segunda passagem pelo hospedeiro, no cultivo $1^{\circ}(\mathrm{B})$. Quando cultivado em MPE, e não expostos à temperatura elevada, houve manutenção na quantidade de UFC até o $20^{\circ}$ cultivo, e no cultivo $1^{\circ}(\mathrm{B})$, a quantidade de UFC aumentou aproximadamente $57 \%$. O mesmo ocorreu após a exposição a $30^{\circ} \mathrm{C}$, que apesar da redução geral na viabilidade, houve um aumento na tolerância à temperatura após a segunda passagem pelo inseto. Na comparação entre os meios, BDA proporcionou maior tolerância em $1^{\circ}(\mathrm{A})$ e $1^{\circ}(\mathrm{B})$ (Tabela 2$)$.

Tabela 2. Unidades formadoras de colônias de Beauveria bassiana, com conídios provenientes de sucessivos cultivos em meio BDA (batata, dextrose, ágar) e ME (meio de Alphitobius diaperinus), após armazenagem a $30^{\circ} \mathrm{C}$ por 15 dias.

\begin{tabular}{clllllllll}
\hline \multirow{2}{*}{ Isolado } & \multirow{2}{*}{ Cultivo } & \multicolumn{3}{c}{ Não expostos a $30^{\circ} \mathrm{C}^{1}$} & \multicolumn{5}{c}{ Expostos a $30^{\circ} \mathrm{C}^{1}$} \\
\cline { 2 - 9 } & & \multicolumn{2}{c}{$\mathrm{BDA}$} & & $\mathrm{MPE}$ & & $\mathrm{BDA}$ & $\mathrm{MPE}$ \\
\hline \multirow{3}{*}{$\mathrm{CG} 152$} & $1^{\circ}(\mathrm{A})$ & $24,60 \pm 2,05$ & $\mathrm{Bc}$ & $123,00 \pm 1,65$ & $\mathrm{Ab}$ & $28,20 \pm 0,86$ & $\mathrm{Ab}$ & $7,40 \pm 0.25$ & $\mathrm{Bc}$ \\
& $10^{\circ}$ & $50,40 \pm 7,41$ & $\mathrm{Bb}$ & $116,00 \pm 3,59$ & $\mathrm{Ab}$ & $18,00 \pm 2.13$ & $\mathrm{Bc}$ & $35,40 \pm 1,97$ & $\mathrm{Ab}$ \\
& $20^{\circ}$ & $48,00 \pm 2,71$ & $\mathrm{Bb}$ & $119,20 \pm 3,85$ & $\mathrm{Ab}$ & $21,60 \pm 0,68$ & $\mathrm{Bbc}$ & $63,20 \pm 3,45$ & $\mathrm{Aa}$ \\
& $1^{\circ}(\mathrm{B})$ & $236,20 \pm 4,20$ & $\mathrm{Aa}$ & $181,20 \pm 5,77$ & $\mathrm{Ba}$ & $77,60 \pm 3,81$ & $\mathrm{Aa}$ & $65,25 \pm 3,00$ & $\mathrm{Ba}$ \\
\hline \multirow{5}{*}{ Unioeste 40} & $1^{\circ}(\mathrm{A})$ & $109,25 \pm 2,86$ & $\mathrm{Ab}$ & $91,60 \pm 4,84$ & $\mathrm{Bb}$ & $10,20 \pm 0,92$ & $\mathrm{Abc}$ & $3,60 \pm 1,29$ & $\mathrm{Ba}$ \\
& $1^{\circ}$ & $47,80 \pm 3,38$ & $\mathrm{Ac}$ & $18,00 \pm 0,63$ & $\mathrm{Bd}$ & $12,60 \pm 0,68$ & $\mathrm{Ab}$ & $1,40 \pm 0,25$ & $\mathrm{Ba}$ \\
& $2^{\circ}$ & $39,00 \pm 3,12$ & $\mathrm{Ac}$ & $49,40 \pm 3,15$ & $\mathrm{Ac}$ & $19,00 \pm 1,59$ & $\mathrm{Aa}$ & $1,40 \pm 0,25$ & $\mathrm{Ba}$ \\
& $1^{\circ}(\mathrm{B})$ & $128,00 \pm 8,48$ & $\mathrm{Aa}$ & $115,00 \pm 4,75$ & $\mathrm{Ba}$ & $19,00 \pm 0,71$ & $\mathrm{Aa}$ & $1,80 \pm 0,20$ & $\mathrm{Ba}$ \\
\hline
\end{tabular}

${ }^{1}$ Médias ( \pm EP) seguidas de mesma letra, minúscula na coluna e maiúscula na linha, para um mesmo tempo, não diferem entre si pelo teste de Tukey $(\mathrm{p}<0,05)$; [CG $152(\mathrm{CV}=8,53 \%)$ e $(\mathrm{CV}=13,38 \%)$; Unioeste $40(\mathrm{CV}=13,23 \%)$ e $(\mathrm{CV}=26,52 \%)$, para não expostos a $30^{\circ} \mathrm{C}$ e expostos a $30^{\circ} \mathrm{C}$ respectivamente $; 1^{\circ}(\mathrm{B})$ primeiro cultivo em meio após a passagem por $\mathrm{A}$. diaperinus; $1^{\circ}(\mathrm{B})$ primeiro cultivo em meio após 20 passagens em meios e uma passagem pelo hospedeiro.

Fonte: Elaboração dos autores.

Para o isolado Unioeste 40, oriundo do meio BDA, e não exposto à temperatura elevada, houve redução de UFC em até $65 \%$ para os conídios de $10^{\circ}$ e $20^{\circ}$ cultivo em relação aos de $1^{\circ}(\mathrm{A})$, entretanto, em $1^{\circ}$ (B) houve um incremento de aproximadamente três vezes em relação ao $20^{\circ}$ cultivo. Para os conídios oriundos de MPE, os menores números de
UFC também foram observados para conídios de $10^{\circ}$ e $20^{\circ}$ cultivos, com aumento significativo em $1^{\circ}(\mathrm{B})$. Na comparação entre os meios, os conídios provenientes de BDA originaram maior quantidade de UFC, exceto no $20^{\circ}$ cultivo que não diferiu de MPE (Tabela 2). 
A exposição dos conídios do isolado Unioeste 40 a temperatura de $30^{\circ} \mathrm{C}$ afetou drasticamente sua viabilidade, com redução geral no número de UFC superior a $90 \%$ para os de BDA e de $98 \%$ para os de MPE. Para os conídios de MPE não houve diferença entre os cultivos, e para os de BDA, os maiores valores foram obtidos nos cultivos $20^{\circ}$ e $1^{\circ}(\mathrm{B})$. Na comparação entre os meios, BDA foi superior em todos os cultivos (Tabela 2).

$\mathrm{O}$ cultivo em meio BDA proporcionou maior termotolerância aos dois isolados avaliados na maioria dos cultivos. Essa característica pode estar relacionada a uma menor variabilidade e disponibilidade de nutrientes no meio BDA, pois segundo Rangel et al. (2008), o estresse nutricional pode estar relacionado com uma maior termotolerância.

Os conídios cultivados sob condições limitantes de nutrientes podem concentrar maior quantidade de trealose (LENG et al., 2011), que é um carboidrato cujo acúmulo nos conídios confere maior termotolerância aos fungos (HALLSWORTH; MARGAN, 1995; SINGER; LINDQUIST, 1998). Além disso, a adição de carboidrato no meio de cultivo também favorece o acúmulo de trealose nas células fúngicas (KIM; JE; ROH, 2010), o que pode explicar a maior tolerância proporcionada dos conídios cultivados em BDA, composto por dextrose e batata, fonte de carboidratos e amido, que somados correspondem a $30 \%$ da composição do meio (ALVES et al., 1998).

Os resultados obtidos no presente trabalho sugerem que a passagem do fungo pelo hospedeiro, assim como a manipulação nutricional podem favorecer a manutenção e/ou aumento da tolerância à temperatura. Esse fato leva a possibilidade de aprimorar a qualidade da produção de fungos em larga escala, resultando em patógenos mais tolerantes, pois uma das principais razões da redução na vida útil dos fungos é a sensibilidade a altas temperaturas (DEVI et al., 2005; FERNANDES et al., 2007; KIM et al., 2008).
3. Compatibilidade entre Azoxistrobina e Beauveria bassiana: A interação entre os sucessivos cultivos e os meios foi significativa, afetando a viabilidade de Beauveria bassiana após a exposição ao fungicida azoxistrobina (CG152: $\mathrm{F}=30,508$; $\mathrm{gl}=3 ; \mathrm{p}=0,0000$ para não expostos ao fungicida; $\mathrm{F}=46,164 ; \mathrm{gl}: 3 ; \mathrm{p}=0,0000$ para expostos ao fungicida). (Unioeste 40: $\mathrm{F}=14,476 ; \mathrm{gl}=3 ; \mathrm{p}=0,000$ para não expostos ao fungicida; $\mathrm{F}=125,384 ; \mathrm{gl}=3$; $\mathrm{p}=0,0000$ para expostos ao fungicida) para testes de germinação e (CG152: $\mathrm{F}=2,977 ; \mathrm{gl}=3 ; \mathrm{p}=0,0472$ para não expostos ao fungicida; $\mathrm{F}=5,228 ; \mathrm{gl}=3$; $\mathrm{p}=0,005$ para expostos ao fungicida). (Unioeste 40 : $\mathrm{F}=129,248 ; \mathrm{gl}=3 ; \mathrm{p}=0,0000$ para não expostos ao fungicida; $F=2,977 ; g l=3 ; p=0,0472$ para expostos ao fungicida) para testes de UFC. Os conídios do isolado CG 152, provenientes do meio BDA, quando foram expostos ao fungicida, obtiveram, de um modo geral, viabilidade inferior a $5 \%$ e não diferiram entre os cultivos. Já em MPE, as passagens do fungo pelo hospedeiro favoreceram um aumento da tolerância ao fungicida, e foram superiores aos conídios originados em BDA. Para os conídios (Unioeste 40) expostos ao fungicida, originados de cultivos em MPE, não houve germinação no $10^{\circ}$ cultivo. Após a segunda passagem pelo hospedeiro, em $1^{\circ}(\mathrm{B})$, houve um aumento da tolerância ao fungicida, com aproximadamente $55 \%$ dos conídios viáveis (Tabela 3).

A maior tolerância ao fungicida, para CG 152 e Unioeste 40, na maioria dos cultivos foi observada para os conídios obtidos em MPE, o que indica que esse meio pode ter fornecido melhores condições nutricionais ao fungo, beneficiando-o de alguma forma. Esse favorecimento pode ter ocorrido pelo acúmulo de nutrientes ou pela existência de alguma substância ou elemento essencial no processo de desintoxicação do fungo metabolizando o fungicida e aumentando a velocidade de germinação.

Tabela 3. Germinação (\%) e Unidade Formadora de 
Colônia de Beauveria bassiana, com conídios provenientes de sucessivos cultivos em meio BDA (batata, dextrose, ágar) e MPE (meio para produção de esporos), não expostos e expostos ao fungicida azoxistrobina.

\begin{tabular}{|c|c|c|c|c|c|c|c|c|c|}
\hline \multirow[t]{2}{*}{ Isolado } & \multirow[t]{2}{*}{ Cultivo } & \multicolumn{4}{|c|}{${ }^{1}$ Não exposto ao fungicida } & \multicolumn{4}{|c|}{${ }^{1}$ Exposto ao fungicida } \\
\hline & & \multicolumn{2}{|c|}{ BDA } & \multicolumn{2}{|l|}{ MPE } & \multicolumn{2}{|c|}{ BDA } & \multicolumn{2}{|l|}{ MPE } \\
\hline & & \multicolumn{8}{|c|}{ Germinação } \\
\hline \multirow{4}{*}{ CG152 } & $1^{\circ}(\mathrm{A})$ & $86,75 \pm 1,88$ & $\mathrm{Ba}$ & $93,73 \pm 1,44$ & $\mathrm{Aa}$ & $5,01 \pm 1,76$ & $\mathrm{Ba}$ & $24,40 \pm 3,05$ & $\mathrm{Ab}$ \\
\hline & $10^{\circ}$ & $75,09 \pm 1,32$ & $\mathrm{Bb}$ & $99,12 \pm 0,34$ & $\mathrm{Aa}$ & $0,72 \pm 0,46$ & $\mathrm{Aa}$ & $0,00 \pm 0,00$ & Ac \\
\hline & $20^{\circ}$ & $87,46 \pm 2,86$ & $\mathrm{Ba}$ & $97,71 \pm 0,73$ & $\mathrm{Aa}$ & $4,67 \pm 1,58$ & $\mathrm{Aa}$ & $1,17 \pm 0,45$ & Ac \\
\hline & $1^{\circ}(\mathrm{B})$ & $57,72 \pm 2,99$ & $\mathrm{Bc}$ & $95,46 \pm 0,97$ & $\mathrm{Aa}$ & $0,00 \pm 0,00$ & $\mathrm{Ba}$ & $35,20 \pm 3,66$ & $\mathrm{Aa}$ \\
\hline \multirow{4}{*}{ Unioeste 40} & $1^{\circ}(\mathrm{A})$ & $73,01 \pm 1,71$ & $\mathrm{Bc}$ & $93,08 \pm 2,32$ & $\mathrm{Aa}$ & $0,44 \pm 0,26$ & $\mathrm{Bb}$ & $16,92 \pm 1,60$ & $\mathrm{Ab}$ \\
\hline & $10^{\circ}$ & $80,00 \pm 0,89$ & Ac & $80,13 \pm 3,52$ & $\mathrm{Ab}$ & $7,77 \pm 2,74$ & Aa & $0,00 \pm 0,00$ & $\mathrm{Bc}$ \\
\hline & $20^{\circ}$ & $88,08 \pm 0,53$ & $\mathrm{Ab}$ & $93,56 \pm 2,79$ & $\mathrm{Aa}$ & $9,72 \pm 0,70$ & $\mathrm{Ba}$ & $17,63 \pm 1,63$ & $\mathrm{Ab}$ \\
\hline & $1^{\circ}(\mathrm{B})$ & $99,02 \pm 0,36$ & $\mathrm{Aa}$ & $95,10 \pm 0,84$ & $\mathrm{Aa}$ & $0,00 \pm 0,00$ & $\mathrm{Bb}$ & $55,38 \pm 3,12$ & $\mathrm{Aa}$ \\
\hline & \multicolumn{9}{|c|}{ Unidade Formadora de Colônia } \\
\hline \multirow{4}{*}{ CG152 } & $1^{\circ}(\mathrm{A})$ & $96,25 \pm 6,22$ & $\mathrm{Ba}$ & $133,2 \pm 4,33$ & $\mathrm{Aa}$ & $62,60 \pm 3,98$ & $\mathrm{Ba}$ & $84,60 \pm 4,28$ & Aa \\
\hline & $10^{\circ}$ & $86,20 \pm 5,22$ & $\mathrm{Bab}$ & $148,40 \pm 4,58$ & $\mathrm{Aa}$ & $10,40 \pm 1,21$ & $\mathrm{Bc}$ & $41,60 \pm 5,15$ & $\mathrm{Ab}$ \\
\hline & $20^{\circ}$ & $70,00 \pm 6,94$ & $\mathrm{Bbc}$ & $129,00 \pm 1,62$ & $\mathrm{Aa}$ & $34,80 \pm 2,44$ & $\mathrm{Bb}$ & $79,80 \pm 6,52$ & $\mathrm{Aa}$ \\
\hline & $1^{\circ}(\mathrm{B})$ & $51,80 \pm 5,76$ & $\mathrm{Bc}$ & $104,00 \pm 5,24$ & $\mathrm{Ab}$ & $30,40 \pm 3,18$ & $\mathrm{Bb}$ & $79,20 \pm 6,52$ & $\mathrm{Aa}$ \\
\hline \multirow{4}{*}{ Unioeste 40} & $1^{\circ}(\mathrm{A})$ & $44,60 \pm 5,08$ & $\mathrm{Bc}$ & $100,80 \pm 8,66$ & $\mathrm{Ab}$ & $29,20 \pm 2,21$ & $\mathrm{Bc}$ & $54,80 \pm 3,32$ & $\mathrm{Ab}$ \\
\hline & $10^{\circ}$ & $127,00 \pm 3,64$ & $\mathrm{Aa}$ & $35,00 \pm 3,40$ & $\mathrm{Bd}$ & $112,00 \pm 1,14$ & $\mathrm{Aa}$ & $3,00 \pm 0,90$ & $\mathrm{Bd}$ \\
\hline & $20^{\circ}$ & $84,60 \pm 2,47$ & $\mathrm{Ab}$ & $65,80 \pm 3,74$ & $\mathrm{Bc}$ & $79,00 \pm 3,42$ & $\mathrm{Ab}$ & $36,50 \pm 2,91$ & $\mathrm{Bc}$ \\
\hline & $1^{\circ}(\mathrm{B})$ & $24,00 \pm 1,77$ & $\mathrm{Bd}$ & $127,40 \pm 6,91$ & $\mathrm{Aa}$ & $23,40 \pm 1,51$ & $\mathrm{Bc}$ & $82,00 \pm 2,29$ & $\mathrm{Aa}$ \\
\hline
\end{tabular}

${ }^{1}$ Médias ( \pm erro padrão) seguidas de mesma letra, minúscula na coluna e maiúscula na linha, não diferem entre si pelo teste de Tukey (p<0,05); [Germinação CG 152 (CV=15,07\%) e (CV=39,69\%); Unioeste 40 (CV=4,44\%) e (CV=25,17\%); UFC CG $152(\mathrm{CV}=11,35 \%)$ e $(\mathrm{CV}=16,35 \%)$; Unioeste $40(\mathrm{CV}=14,40 \%)$ e $(\mathrm{CV}=10,15 \%)$, para não expostos ao fungicida e expostos ao fungicida respectivamente]; $1^{\circ}(\mathrm{A})$ primeiro cultivo em meio após a passagem pelo hospedeiro; $1^{\circ}(\mathrm{B})$ primeiro cultivo em meio, após 20 passagens em meios e uma passagem pelo hospedeiro.

Fonte: Elaboração dos autores.

Alguns produtos podem influenciar os fungos entomopatogênicos, afetando não só a viabilidade, mas também o crescimento vegetativo e a esporulação, ou até mesmo a expressão gênica, alterando a sua virulência (ALVES et al., 1998). Entretanto, o efeito de alguns fungicidas sobre os fungos pode variar em função da espécie ou linhagem do patógeno, natureza química dos produtos e das concentrações utilizadas, o que exige testes preliminares em relação à suscetibilidade do isolado ao produto químico utilizado na lavoura (SOSA-GÓMEZ; MOSCARDI, 2003). Shapiro-llan et al. (2002) testaram a resistência de sete isolados de $B$. bassiana a fenbuconazole, e observaram que um dos isolados foi fortemente inibido pelo produto.

No presente trabalho, o fungicida interferiu na viabilidade do fungo, variando entre os isolados testados. O cultivo em meio mais nutritivo e também a passagem do fungo pelo hospedeiro foram capazes de elevar a tolerância ao fungicida. Esse fato nunca foi avaliado antes em outros trabalhos, e é de extrema importância, pois manter e/ou aumentar a compatibilidade entre os agentes de controle possibilita sua aplicação em conjunto ou sequencial, disponibilizando mais ferramentas para o manejo das populações de pragas.

A avaliação da germinação é o parâmetro mais importante para avaliar a compatibilidade entre os produtos químicos e fungos entomopatogênicos (NEVES et al., 2001; HIROSE et al., 2001), visto que o início da infecção está relacionado à capacidade de germinação do fungo e sua penetração no hospedeiro (OLIVEIRA; NEVES; KAWAZOE, 2003). 
Entretanto, a avaliação de UFC também apresenta grande importância, pois os produtos químicos podem causar apenas um atraso na germinação dos conídios sobreviventes, sem afetar a viabilidade (SILVA; NEVES, 2005). Esse fato foi verificado no presente trabalho, onde a redução do número de UFC após a exposição ao fungicida foi menor quando comparada a germinação, o que mostra que nem todos os conídios que não germinaram estavam inviáveis.

Observando o número de UFC obtido dos conídios expostos e não expostos ao fungicida, foi possível notar a sensibilidade do isolado CG 152 ao produto químico em todos os cultivos, especialmente no $10^{\circ}$, onde os conídios originados tanto em meio BDA, como em MPE foram os mais sensíveis ao fungicida. Esse fato, que também ocorreu na geminação, pode estar relacionado com as sucessivas passagens do fungo pelo meio de cultivo, entretanto, após um maior número de passagens, o fungo pode ter se adaptado as condições nutricionais, refletindo-se em maior tolerância ao produto químico (Tabela 3).

Após a exposição ao fungicida, os conídios de Unioeste 40 oriundos de BDA também sofreram alteração no número de UFC, e semelhante ao que ocorreu com os conídios não expostos ao fungicida, os de $10^{\circ}$ cultivo foram responsáveis pelo maior número de $\mathrm{UFC}$, e os de $1^{\circ}(\mathrm{B})$ e $1^{\circ}(\mathrm{A})$, obtiveram os menores valores. Para os conídios originados em MPE, os de $1^{\circ}(\mathrm{B})$ foram os mais tolerantes, já para os de $10^{\circ}$, observou-se o menor número de UFC, assim como ocorreu aos conídios não expostos ao fungicida. Na comparação entre os meios, MPE proporcionou maior tolerância em $1^{\circ}(\mathrm{A})$ e $1^{\circ}(\mathrm{B})$, e BDA melhor tolerância para os conídios de $10^{\circ} \mathrm{e}$ $20^{\circ}$ (Tabela 3).

Para os dois isolados avaliados nesse estudo houve grande redução na germinação dos conídios após o contato com o fungicida, entretanto o número de UFC foi menos afetado. Essas diferenças podem ser devido à redução do efeito dos produtos aos conídios ao longo do tempo, pois a germinação foi avaliada com 20 horas, enquanto as UFC foram avaliadas após quatro dias. Da mesma maneira, Griffin (1994) também observou que os efeitos de muitos inseticidas sobre o crescimento do fungo podem diminuir gradualmente ao longo do tempo.

A incompatibilidade entre o fungo e alguns pesticidas, pode ocorrer quando tanto a germinação, quanto o número de UFC são afetados após o contato com o fungicida. Esse fato foi observado para Unioeste 40 no $10^{\circ}$ cultivo em meio MPE e nos cultivos $1^{\circ}(\mathrm{A})$ e $1^{\circ}(\mathrm{B})$ em BDA, e para o isolado CG 152 no $10^{\circ}$ em BDA. Os conídios originados nesses cultivos obtiveram os menores valores de germinação e UFC, sugerindo não ser apenas um atraso na germinação, e sim a total inativação dos conídios pelo fungicida.

A variabilidade entre as respostas de diferentes isolados pertencentes a uma mesma espécie de fungo entomopatogênico em relação a diversos parâmetros biológicos, inclusive para a sensibilidade a produtos químicos sintéticos (OLMERT; KENNETH, 1974; LIU et al., 1993), pode estar ligada à diversidade genética existente entre eles. Neste trabalho observou-se que, além da variabilidade genética, as condições de cultivo, o número de vezes em que o fungo é cultivado in vitro e a passagem pelo hospedeiro são fatores que podem influenciar na sensibilidade do fungo ao fungicida.

\section{Conclusão}

Os cultivos sucessivos de $B$. bassiana in vitro e as condições nutricionais do meio afetaram a tolerância à temperatura, à radiação UV e a sensibilidade ao fungicida azoxistrobina, com respostas diferentes entre os isolados.

Os maiores níveis de tolerância após as condições de estresse, na maioria dos casos, foram obtidos pelo isolado CG 152, cultivado em MPE, e Unioeste 40, em BDA.

A tolerância à temperatura e à radiação UV, e a tolerância de $B$. bassiana a azoxistrobina 
que foram atenuadas pelos cultivos sucessivos, foram restauradas após a passagem do fungo pelo hospedeiro, entretanto, isso depende do isolado e do meio onde ocorreram os cultivos.

\section{Agradecimentos}

Ao CNPq pela bolsa de mestrado concedida ao primeiro autor.

\section{Referências}

ALVES, S. B.; ALMEIDA, J. E. M.; MOINO JÚNIOR, A.; ALVES, L. F. A. Técnicas de laboratório. In: ALVES, S. B. (Ed.). Controle microbiano de insetos. Piracicaba: FEALQ, 1998. p. 637-710.

ALVES, S. B.; PEREIRA, R. M. Produção de fungos entomopatogênicos. In: ALVES, S. B. (Ed.). Controle microbiano de insetos. Piracicaba: FEALQ, 1998. p. 845-867.

ALVES, S. B.; LECUONA, R. E. Epizootiologia aplicada ao controle microbiano de insetos. In: ALVES, S. B. (Ed.). Controle microbiano de insetos. Piracicaba: FEALQ, 1998. p. 97-163.

BRAGA, G. U. L.; FLINT, S. D.; MILLER, C. D.; ANDERSON, A. J.; ROBERTS, D. W. Variability in response to UV-B among species and strains of Metarhizium isolated from sites at latitudes from $61^{\circ} \mathrm{N}$ to $54^{\circ}$ S. Journal of Invertebrate Pathology, San Diego, v. 78, n. 2, p. 98-108, 2001.

BRAGA, G. U. L.; RANGEL, D. E. N.; FLINT, S. D.; MILLER, C. D.; ANDERSON, A. J.; ROBERTS, D. W. Damage and recovery from UV-B exposure in conidia of the entomopathogens Verticillium lecanii and Aphanocladium album. Mycologia, New York, v. 94, n. 6, p. 912-920, 2002.

CHELICO, L.; KHACHATOURIANS, G. G. Isolation and characterization of nucleotide excision repair deficient mutants of the entomopathogenic fungus, Beauveria bassiana. Journal of Invertebrate Pathology, San Diego, v. 98, n. 1, p. 93-100, 2008.

DEVI, K. U.; SRIDEVI, V.; MOHAN, C. M.; PADMAVATHI, J. Effect of high temperature and water stress on in vitro germination and growth in isolates of the entomopathogenic fungus Beauveria bassiana (Bals.) Vuillemin. Journal of Invertebrate Pathology, San Diego, v. 88, n. 3, p. 181-189, 2005.
FARGUES, J.; GOETTEL, M. S.; SMITS, N.; OUEDRAOGO,A.; VIDAL, C.; LACEY, L. A.; LOMER, C. J.; ROUGIER, M. Variability in susceptibility to simulated sunlight of conidia among isolates of entomopathogenic hyphomycetes. Mycopathologia, Den Haag, v. 135, n. 3, p. 171-181, 1996.

FERNANDES, E. K. K.; RANGEL, D. E. N.; MORAES, A. M. L.; BITTENCOURT, V. R. E. P.; ROBERT, D. W. Variability in tolerance to UV-B radiation among Beauveria spp. isolates. Journal of Invertebrate Pathology, San Diego, v. 96, n. 3, p. 237-243, 2007.

FERREIRA, D. F. Programa Sisvar versão 5.1. Lavras: Departamento de Ciências Exatas da Universidade Federal de Lavras, 2007. 664 p.

FERRON, P. Fungal control. In: KERKUT, G. A.; GILBERT, L. I. (Ed.). Comprehensive insect physiology, biochemistry and pharmacology. Oxford: Pergamon, v. $12,1985.735 \mathrm{p}$.

GRIFFIN, D. H. Fungal physiology. New York: WileyLiss, 1994. 458 p.

HALLSWORTH, J. E.; MAGAN, N. Manipulation of intracellular glycerol and erythritol enhances germination of conidia at low water availability. Microbiology, Washington, v. 141, n. 5, p. 1109-1115, 1995.

HIROSE, E.; NEVES, P. M. O. J.; ZEQUI, J. A.; MARTINS, C. L. H.; PERALTA, C. H.; MOINO, A. Effect of biofertilizers and Neem Oil on the Entomopatogenic fungi Beauveria bassiana (Bals.) Vuill. and Metarhizium anisopliae (Metsch.) Sorok. Brazilian Archives of Biology and Technology, Curitiba, v. 44, n. 4, p. 419-423, 2001.

KIM, J. S.; LEE, H. Y.; CHUNG, B. J.; JE, Y. H. Method for enhancing the thermal tolerance of entomopathogenic fungal spores, blastospores and enzymes. PCT Patent Publication No. WO/2008/063011 (Korean Patent No. 10-0835689-0000). nov. 2007, 29 maio 2008. Disponível em: <http://www.lens.org/images/patent/ WO/2008063011/A1/WO_2008_063011_A1.pdf $>$. Acesso em: 28 nov. 2012.

KIM, J. S.; JE, Y. H.; ROH, J. Y. Production of thermotolerant entomopathogenic Isaria fumosorosea SFP-198 conidia in corn-corn oil mixture. Journal of Industrial Microbiology e Biotechnology, Hampshire, v. 37, n. 4, p. 419-423, 2010.

LATCH, G. C. M. Studies on the susceptibility of Oryctes rhinoceros to some entomogenous fungi. Entomophaga, Switzerland, v. 21, n. 1, p. 31-38, 1976.

LEITE, L. G.; BATISTA FILHO, A.; ALMEIDA, J. E. M.; ALVES, S. B. Produção de fungos entomopatogênicos. Ribeirão Preto: A. S. Pinto, 2003. 92 p. 
LENG, Y.; PENG, G.; CAO, Y.; XIA,Y. Genetically altering the expression of neutral trehalase gene affects conidiospore thermotolerance of the entomopathogenic fungus Metarhizium acridum. BMC Microbiology, London, v. 11, n. 32, p. 1-8, 2011.

LIU, Z. Y.; MILNER, R. J.; MCRAE, C. F.; LUTTON, G. $\mathrm{G}$. The use of dodine in selective media for the isolation of Metarhizium spp. from soil. Journal of Invertebrate Pathology. San Diego, v. 62, n. 3, p. 248-251, 1993.

MOORE, D.; BRIDGE, P. D.; HIGGINS, P. M.; BATEMAN, R. P.; PRIOR, C. Ultra-violet radiation damage to Metarhizium flavoviride conidia and the protection given by vegetable and mineral oils and chemical sunscreens. Annals of Applied Biology, Warwick, v. 122, n. 3, p. 605-616, 1993.

NASCIMENTO, E.; SILVA, S. H. da, MARQUES, E. dos R.; ROBERTS, D. W.; BRAGA, G. U. L. Quantification of cyclobutane pyrimidine dimers induced by UVB radiation in conidia of the fungi Aspergillus fumigatus, Aspergillus nidulans, Metarhizium acridum and Metarhizium robertsii. Photochemistry and Photobiology, Oxford, v. 20, n. 1, p. 1-8, 2010.

NEVES, P. M. O. J.; HIROSE, E.; TCHUJO, P. T.; MOINO, J. A. Compatibility of entomopathogenic fungi with neonicotinoid insecticides. Neotropical Entomology, Londrina, v. 30, n. 2, p. 263-268, 2001.

OLIVEIRA, G. N.; NEVES, P. M. O. J.; KAWAZOE, L. S. Compatibility between the entomopathogenic fungus Beauveria bassiana and insecticides used in coffee plantations. Scientia Agricola, Piracicaba, v. 60, n. 4, p. 663-667, 2003.

OLMERT, I.; KENNETH, R. G. Sensitivity of the entomopathogenic fungi Beauveria bassiana, Verticillium lecanii and Verticillium sp. to fungicides and insecticides. Environmental Entomology, v. 3, n. 1, p. 33-39, 1974.

PELL, J. K.; EILENBERG, J.; HAJEK, A. E.; STEINKRAUS, D. C. Biology, ecology and pest management potential of Entomophthorales. In: BUTT, T. M.; JACKSON, C.; MAGAN, N. (Ed.). Fungi as biocontrol agents: progress, problems and potential. Wallingford: CAB International, 2001. $390 \mathrm{p}$.

RANGEL, D. E. N.; ANDERSON, A. J.; ROBERTS, D. W. Evaluating physical and nutritional stress during mycelial growth as inducers of tolerance to heat and UV-B radiation in Metarhizium anisopliae conidia. Mycological Research, Cambridge, v. 112, n. 11, p. 13621372, 2008.
RANGEL, D. E. N.; BRAGA, G. U. L.; ANDERSON, A. J.; ROBERTS, D. W. Variability in conidial thermotolerance of Metarhizium anisopliae isolates from different geographic origins. Journal of Invertebrate Pathology, San Diego, v. 88, n. 2, p. 116-125, 2005.

RANGEL, D. E. N.; BYTLER, M. J.; TORABINEJAD, J.; ANDERSON, A. J.; BRAGA, G. U. L.; DAY, A. W.; ROBERTS, D. W. Mutants and isolates of Metarhizium anisopliae are diverse in their relationships between conidial pigmentation and stress tolerance. Journal of Invertebrate Pathology, San Diego, v. 93, n. 3, p. 170182, 2006.

SANTORO, P. H.; NEVES, P. M. O. J.; ALEXANDRE, T. M.; SARTORI, D.; ALVES, L. F. A.; FUNGARO, M. H. Selection of Beauveria bassiana isolates to control Alphitobius diaperinus. Journal of Invertebrate Pathology, San Diego, v. 97, n. 2, p. 83-90, 2008.

SERAFINI, L. A.; BARROS, N. M.; AZEVEDO, J. L. Biotecnologia na agricultura e na indústria. In: AZEVEDO, J. L. (Ed.). O uso dos fungos na biotecnologia. Guaíba: Agropecuária, 2001. p. 93-152.

SHAPIRO-LLAN, D. I.; REILLY, C. C.; HOTCHKISS, M. W.; WOOD, B. W. The potential for enhanced fungicide resistance in Beauveria bassiana through strain and artificial selection. Journal of Invertebrate Pathology, San Diego, v. 81, n. 2, p. 86-93, 2002.

SILVA, R. Z.; NEVES, P. M. O. J. Techniques and parameters used in compatibility tests between Beauveria bassiana (Bals.) Vuill. and in vitro phytosanitary products. Pest Management Science. Oxford, v. 61, n. 7, p. 667-674, 2005.

SINGER, M. A.; LINDQUIST, S. Multiple effects of trehalose on protein folding in vitro and in vivo. Molecular Cell, Cambridge, v. 1, n. 5, p. 639-648, 1998.

SOSA-GOMES, D. R.; MOSCARDI, F. Importância das interações entre agroquímicos e entomopatógenos em programas de MIP. In: SIMPÓSIO DE CONTROLE BIOLÓGICO, 8., 2003, São Pedro, SP. Resumos... São Pedro: Sociedade Entomológica do Brasil, 2003. p. 59.

VANDENBERG, J. D.; CANTONE, F. A. Effect of serial transfer of three strains of Paecilomyces fumosoroseus on growth in vitro, virulence, and host specificty. Journal of Invertebrate Pathology, San Diego, v. 85, p.40-45, 2004. 
